\title{
Effect of injection molded micro-structured polystyrene surfaces on proliferation of MC3T3-E1 cells
}

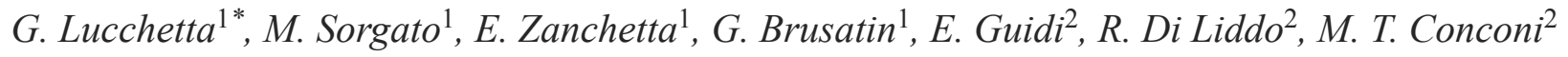 \\ ${ }^{1}$ University of Padua, Department of Industrial Engineering, Via Venezia, 1 - 35131 Padova, Italy \\ ${ }^{2}$ University of Padua, Department of Pharmaceutical and Pharmacological Sciences, Via Marzolo, 5 - 35131 Padova, Italy
}

Received 4 August 2014; accepted in revised form 12 October 2014

\begin{abstract}
In this work, osteoinductive micro-pillared polystyrene surfaces were mass-produced for bone replacement applications, by means of the micro injection molding process. Firstly, the molding process parameters were optimized with a two-level, three-factor central composite face-centered plan to increase the quality of polystyrene micro pillars replication and to maximize the pillars height uniformity over the molded part. Secondly, osteoblastic MC3T3-E1 cells adhesion and proliferation on the replicated substrates were assessed as a function of micro topography parameters, such as pillars diameter, aspect ratio and spacing. Cell morphology and proliferation were evaluated through MTS test after 1, 3 and 7 days from seeding. The experimental results showed that cells adhesion and proliferation is more positively promoted on micro-pillared surfaces compared to flat surfaces, but no correlations were observed between cell proliferation and pillar diameter and spacing.
\end{abstract}

Keywords: processing technologies, micro injection molding, micro topography replication, cells growth

\section{Introduction}

Osseointegration is the process in which an implanted material integrates with living bone, firmly anchoring the implant in place. It assures the clinical success of dental implants and creates anchors for prosthesis, such as prosthetic limbs. Osseointegration depends to a large extent on previous osteoinduction. This last process occurs in the initial part of the implant incorporation and healing response. Bone growth on an implant surface depends on the action of differentiated bone cells. These cells may originate either in pre-existing preosteoblasts/ osteoblasts that are activated by trauma or in cells recruited from primitive mesenchymal cells by osteoinduction [1]. Work by several research groups has shown that biomaterials need to meet very specific requirements in terms of (a) chemical composition, (b) macrostructure and (c) microstructure in order to be osteoinductive [2]. Regarding this last requirement, several studies have shown that numerous cell types react to micro topography [3-5]. Changes in cell adhesion [6,7], alignment $[7,8]$ and proliferation [9] have been reported in the literature. In particular, Kolind et al. [10] conducted a combinatorial screening experimental campaign to identify the effect of several distinct micro-pillared silicon wafers on fibroblast proliferation. They observed that larger $(4-6 \mu \mathrm{m})$ inter-pillar gap sizes reduced fibroblast growth. Smaller (1-2 $\mu \mathrm{m})$ inter-pillar spacing, on the contrary, caused the fibroblasts to proliferate comparable to cells on a non-structured surface.

Polymers have increasingly been used to look at how the elasticity of underlying substrates can be tailored to direct human mesenchymal stem cells (hMSC) differentiation into either neuronal, muscle or bone lineages [11]. Disordered arrays of nanoscale

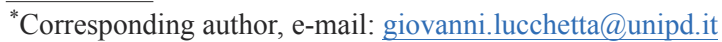
(C) BME-PT
} 
pits on polymethyl methacrylate substrates have been found to induce hMSC differentiation into bone mineral in the absence of osteogenic biochemical cues [12]. hMSC culture on injection molded polycarbonate nano pits have been found to influence filopodia interaction, resulting in reduced spreading and focal adhesion [13].

Angelov et al. [14] have demonstrated that micro injection molding can be used for the mass fabrication of nano-pillared polystyrene (PS) surfaces for hMSC differentiation. However, the effect of the scale sizes (diameter and aspect ratio) as well as the spacing of the pillars on cell adhesion and proliferation needs to be further investigated, especially in relation to micro injection molding replication capabilities. In fact, the aspect ratio achievable in replicating micro features is one of the most important characteristics of any micro fabrication process and determines the manufacturing constraints of a given process-material combination. Molding micro features with high aspect ratios is still a challenge [15] because the high surface-to-volume ratio typical of micro cavities makes the melt solidify much faster than in the conventional process, thus leading to an incomplete replication. Concerning the achievable aspect ratios, there is a limitation that is a function of geometry of the micro features, their position on the part, the polymer type and the process parameters $[16,17]$. Moreover, to achieve the required accuracy the process needs to be optimized, as the quality of micro molded parts can be largely modified by different selections of process parameters. Griffiths et al. [18] indicated that the selection of high process settings can significantly improve the replication quality. In particular, the mold temperature was identified as the most significant parameters, due to its influence on the viscosity of the polymer melt [19]. An increase in mold temperature, especially above the glass transition temperature of the material, could lessen the thermal gradient between the mold and the molten polymer [20,21].

In this work, the micro injection molding process was employed and optimized to produce micro-pillared PS surfaces for bone replacement applications. Directly patternable hybrid materials were used for micro-structured mold inserts fabrication. Pillars diameter, aspect ratio and spacing were varied in order to evaluate the topography effect on osteoblastic MC3T3-E1 cells adhesion and proliferation.

\section{Experimental}

\subsection{Materials}

The material used for injection molding was a commercial polystyrene resin PS Crystal 1540, manufactured by TOTAL, with a MFI $\left(200^{\circ} \mathrm{C}-5 \mathrm{~kg}\right)$ of $12 \mathrm{~g} / 10 \mathrm{~min}$ and a $T_{\mathrm{g}}$ of $100^{\circ} \mathrm{C}$. This resin was chosen due to its high flowability, good biocompatibility, high optical clarity, high transparency and high impact strength. Furthermore, polystyrene was not treated for cell cultures to better discriminate the effects of micro-pillared on cell adhesion and growth. The molded products were cylindrical supports with a diameter of $5.9 \mathrm{~mm}$ and a thickness of $2 \mathrm{~mm}$, with different micro-structured surface topographies.

\subsection{Lithography and resist development}

The tooling inserts were manufactured from rectangular pieces of steel $39 \mathrm{NiCrMo} 3$, according to the following operations: lapping, machining and photolithography. The initial rectangular pieces of steel were lapped to obtain a polish surface for the subsequent deposition of the masking film. The steel was initially sandpapered (grit: 180, 600, 1200) and then refined with abrasive particles $(6,3,1 \mathrm{~mm})$ to eventually obtain a surface with $R_{\mathrm{a}}<0.050 \mu \mathrm{m}$. The lapped inserts were then machined to obtain the desired shape to mount it on the fixed plate of the mold. The inserts were eventually coated with a silica-zirconia directly patternable resist, which was synthesized starting with 3-(trimethoxysilyl)propyl methacrylate (TMSPM) and $\mathrm{Zr}$-butoxide $\left(\mathrm{Zr}(\mathrm{OBut})_{4}\right)$ as sol-gel precursors. The system was obtained as follows: TMSPM was firstly hydrolyzed in acidic conditions for one hour at room temperature (TMSPM: $\mathrm{H}_{2} \mathrm{O}: \mathrm{HCl}=1: 3: 0.01$ molar ratio). $\mathrm{Zr}(\mathrm{OBut})_{4}$ and Metacrylic acid (MAA) were separately left stirring for five minutes, before being added to the hydrolyzed TMSPM solution (TMSPM: $\operatorname{Zr}(\mathrm{OBut})_{4}=$ 1:0.5 molar ratio). The final sol was stirred for one hour. Tetrahydrofuran solvent was added to the sol to reach the desired concentration of $110 \mathrm{~g} / \mathrm{L}$ $\mathrm{SiO}_{2}+\mathrm{ZrO}_{2}$. IRGACURE 369 photoinitiator was finally added $1 \%$ molar (with respect to TMSPM) to the sol before UV exposure. The sol was finally filtrated through a $0.2 \mu \mathrm{m}$ filter in order to remove large particles and get a better film quality.

After spin coating at different speeds, according to the final target thickness, each insert was exposed 
Table 1. Average values for holes depth and interspace

\begin{tabular}{|l|c|c|c|}
\hline \multicolumn{1}{|c|}{ Insert } & $\begin{array}{c}\text { Depth } \\
{[\boldsymbol{\mu \mathrm { m } ]}}\end{array}$ & $\begin{array}{c}\text { Interspace } \\
{[\boldsymbol{\mu \mathrm { m } ]}]}\end{array}$ & Aspect ratio \\
\hline $2-8$ & $0.990 \pm 0.147$ & $7.999 \pm 0.048$ & 0.495 \\
\hline $3-9$ & $1.525 \pm 0.033$ & $9.012 \pm 0.058$ & 0.508 \\
\hline $4-10 \mathrm{a}$ & $0.990 \pm 0.041$ & $10.020 \pm 0.065$ & 0.248 \\
\hline $4-10 \mathrm{~b}$ & $1.789 \pm 0.094$ & $10.063 \pm 0.091$ & 0.477 \\
\hline
\end{tabular}

to a $4 \mathrm{~J} / \mathrm{cm}^{2}$ ultraviolet dose through a mask, which contains the desired pattern. Three different patterns of equally spaced holes were realized over the whole circular area:

- Pattern 2-8: $2 \mu \mathrm{m}$ diameter holes interspaced by $8 \mu \mathrm{m}$,

- Pattern 3-9: $3 \mu \mathrm{m}$ diameter holes interspaced by $9 \mu \mathrm{m}$,

- Pattern 4-10: $4 \mu \mathrm{m}$ diameter holes interspaced by $10 \mu \mathrm{m}$. Two inserts having different resist thickness (to vary the holes aspect ratio) were produced with this pattern.

Following UV exposure, the resist was developed for $15 \mathrm{~s}$ in a solution of ethanol:acetone 100:1 and dried by blowing air. This was followed by resist film hard-baking at $100^{\circ} \mathrm{C}$ for 1 hour.

Every insert was then characterized by means of an Atomic Force Microscope (DME, DS 95-200) having a nominal scanning range of $200 \times 200 \mu \mathrm{m}^{2}$. All inserts were measured in three areas along the diameter of the molded part (close to gate, in the center and at the opposite side from the gate) for a total of 15 measurements per insert. Average values for the holes depth and interspace are reported in Table 1.

\subsection{Polymer replication}

Each micro-structured steel insert was housed in a custom-built steel mold. A state-of-the-art micro injection molding machine (Wittmann-Battenfeld, MicroPower 15) was used for the molding experiments. The machine is characterized by a maximum clamping force of $150 \mathrm{kN}$ and a maximum injection speed of $750 \mathrm{~mm} / \mathrm{s}$. The plasticizing screw has a diameter of $14 \mathrm{~mm}$ and the injection plunger has a diameter of $5 \mathrm{~mm}$.

A two-level, three-factor central composite facecentered plan was used to optimize the process using the insert $4-10 \mathrm{~b}$. The optimal process parameters determined for this insert have then been used to mold all of the other patterns. The factors investigated were injection speed $\left(V_{\text {inj }}\right)$, mold temperature $\left(T_{\mathrm{m}}\right)$ and holding pressure $\left(P_{\text {hold }}\right)$, as their influence
Table 2. Process parameter settings

\begin{tabular}{|c|c|c|c|}
\hline Level & $\begin{array}{c}\mathbf{V}_{\text {inj }} \\
{[\mathbf{m m} / \mathbf{s}]}\end{array}$ & $\begin{array}{c}\mathbf{T}_{\mathbf{m}} \\
{\left[{ }^{\circ} \mathbf{C}\right]}\end{array}$ & $\begin{array}{c}\mathbf{P}_{\text {hold }} \\
{[\mathbf{b a r}]}\end{array}$ \\
\hline-1 & 250 & 50 & 100 \\
\hline+1 & 500 & 90 & 200 \\
\hline
\end{tabular}

on replication quality has been repeatedly reported in the literature $[18,22]$. The choices of the upper and lower values for the factors derived from a literature review, recommendations of the material supplier and technological limits of the available experimental setup (Table 2). In particular, the lower and higher values for $V_{\text {inj }}$ were selected considering a robust molding window, which was defined in preliminary tests.

The nozzle, front, middle, and rear temperature settings were: $240,230,220$, and $200^{\circ} \mathrm{C}$ respectively.

For each run, the parts produced in the first 20 cycles were discarded in order to stabilize the process, and then the following part was collected for metrological characterization. Each run of the designed experiments was replicated twice in a completely randomized order for a total of 30 produced samples, with the aim of minimizing the interference of external variability sources. The material was taken from a single batch.

The response variable for this analysis was chosen to be the replicated height of the pillars, measured by means of a state-of-the-art 3D optical profiler (Sensofar PLu neox) operating in confocal mode with $20 \times$ and $100 \times$ objectives. All replications of each treatment have been measured in three areas along the diameter of the molded part (Figure 1). The

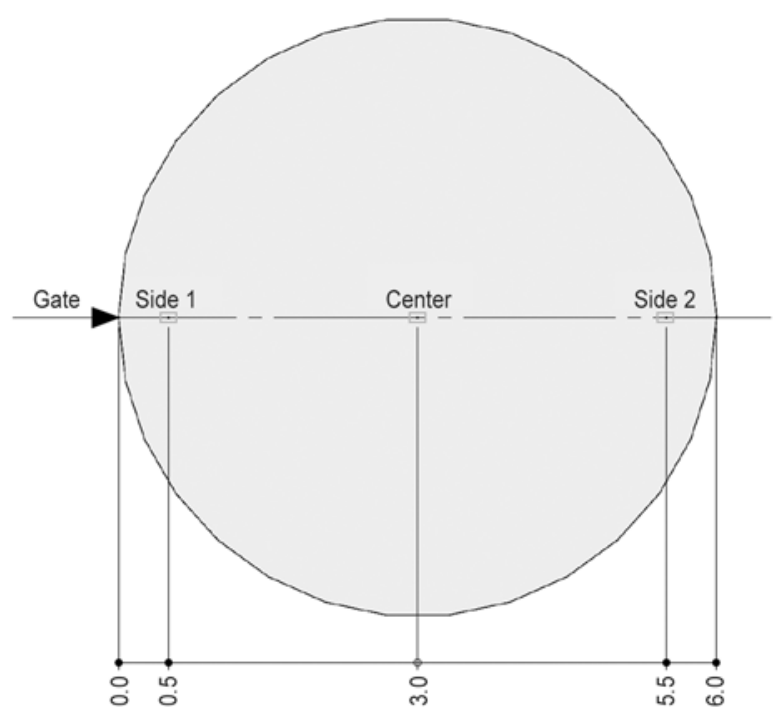

Figure 1. Measured areas for the characterization of the height of micro pillars. All quotes in $\mathrm{mm}$. 

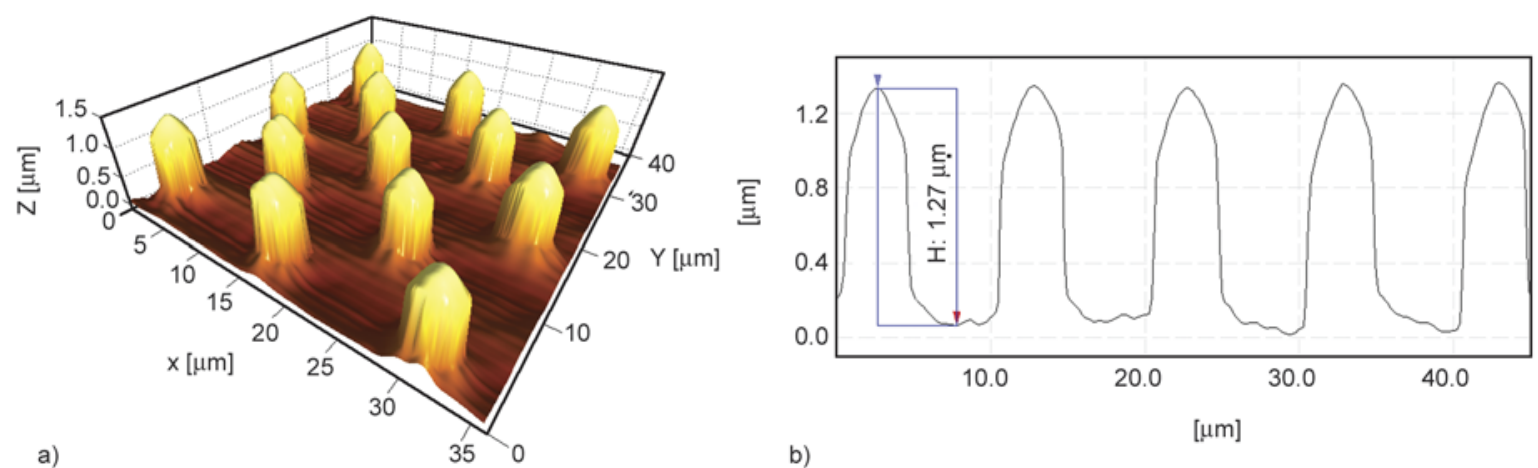

Figure 2. (a) Topography of a 4-10b insert replication in the Side 2 area; (b) height profile of the 5 measured micro pillars of a $4-10 b$ insert in the Side 2 area

scans have an area of $127.32 \times 95.45 \mathrm{~mm}^{2}$. The positions of the measured areas are the same used for the inserts measurements.

Figure 2 shows the topography of the surface of a molded part in the scanned area. In each scanned area the profiles of 5 micro pillars were taken into consideration, for a total of 15 micro pillars analyzed for each replication. The height of the pillars was measured with 1-cursor pair using the image processing software SPIP 6.2.6 (Image Metrology).

\subsection{Cell cultures}

The osteoblastic cell line MC3T3-E1 was purchased from DSMZ (Leibniz-Institut DSMZ-Deutsche Sammlung von Mikroorganismen und Zellkulturen $\mathrm{GmbH}$ ) and cultured with $\alpha$-minimal essential medium ( $\alpha$-MEM, Life Technologies, Baltimore, $\mathrm{MD}$, cod. 22561-021) containing 10\% fetal bovine serum (FBS, Sigma, ST. Louis, MO, cod. F9665), and $1 \%$ penicilline/streptomycine (Sigma, cod. P0781). Cells were grown at $37^{\circ} \mathrm{C}$ in a humid atmosphere with $5 \% \mathrm{CO}_{2}$. Medium was refreshed three times a week. Cells $\left(1.5 \cdot 10^{4}\right.$ cells $\left./ \mathrm{cm}^{2}\right)$ were seeded on pillar-structured polystyrene arrays previously put onto wells of 96-well plates. Cultures grown on nonmodified polystyrene arrays were used as control. After various time points from seeding, cell morphology and proliferation were evaluated.

At $24 \mathrm{~h}$ from seeding, cultures were fixed in 3.7\% formaldehyde for $20 \mathrm{~min}$ at room temperature and then dehydrated with a graded ethanol series. After gold sputtering, samples were observed by a Scanning Electron Microscope (JEOL JSM-6490, Peabody, MA).

\subsection{MTS assay}

To test cell viability, the 3-(4,5-dimethylthiazol-2yl)-5-(3-carboxymethoxyphenyl)-2-(4 sulfophenyl)2H-tetrazolium) (MTS) test (CellTiter $96^{\circledR}$ AQueous One Solution Cell Proliferation Assay; Promega, Austria, cod. G3580) was used, according to the manufacturer's instruction. Briefly, at 1, 3, and 7 days from seeding, $200 \mathrm{uL}$ of cell media, containing 10\% MTS, were added into each well and cells were incubated at $37^{\circ} \mathrm{C}$ for $4 \mathrm{~h}$. Optical density of purple formazan produced in living cells was measured at $490 \mathrm{~nm}$, using a Microplate autoreader EL 311 (BIOTEK instruments Inc., Winooski, Vermont, USA). Results were expressed as number of cells. The linearity of absorbance of formazan over a range of $2.5 \cdot 10^{3}-20 \cdot 10^{3}$ cells was established by determining the linear coefficient $(0.980)$.

Triplicate experiments were performed. The results were expressed as the arithmetic mean \pm standard deviation. Their statistical comparison was performed by analysis of variance, followed by Student's $t$-test.

\section{Results and discussion \\ 3.1. Micro pillars replication}

The primary goal of the performed experimental plan was to identify the factors that influence the replicated height of micro pillars. The ANOVA results for the designed plan indicate that all the factors and their interactions are significant, especially the mold temperature and the holding pressure (Table 3 ). The lack of fit test confirmed that the regression fitted the second-order model. 
Table 3. Estimated regression coefficients for pillars height

\begin{tabular}{|l|c|r|r|c|}
\hline \multicolumn{1}{|c|}{ Term } & Coef & SE Coef & \multicolumn{1}{c|}{ T } & P \\
\hline Constant & 0.319720 & 0.009886 & 32.341 & 0.000 \\
\hline$V_{\text {inj }}$ & 0.026222 & 0.005816 & 4.508 & 0.000 \\
\hline$P_{\text {hold }}$ & 0.094042 & 0.005816 & 16.168 & 0.000 \\
\hline$T_{\mathrm{m}}$ & 0.238988 & 0.005816 & 41.089 & 0.000 \\
\hline$V_{\text {inj }} \cdot V_{\text {inj }}$ & 0.007625 & 0.011470 & 0.665 & 0.514 \\
\hline$P_{\text {hold }} \cdot P_{\text {hold }}$ & 0.023425 & 0.011470 & 2.042 & 0.055 \\
\hline$T_{\mathrm{m}} \cdot T_{\mathrm{m}}$ & 0.176858 & 0.011470 & 15.419 & 0.000 \\
\hline$V_{\text {inj }} \cdot P_{\text {hold }}$ & 0.002723 & 0.006503 & 0.419 & 0.680 \\
\hline$V_{\text {inj }} \cdot T_{\mathrm{m}}$ & 0.010577 & 0.006503 & 1.627 & 0.119 \\
\hline$P_{\text {hold }} \cdot T \mathrm{~m}$ & 0.078952 & 0.006503 & 12.141 & 0.000 \\
\hline
\end{tabular}

Table 4. Replication of the micro holes for the insert 4-10b

\begin{tabular}{|l|c|c|c|}
\hline \multicolumn{1}{|c|}{ Term } & $\begin{array}{c}\text { Holes depth } \\
{[\boldsymbol{\mu \mathbf { m } ]}}\end{array}$ & $\begin{array}{c}\text { Pillars height } \\
{[\boldsymbol{\mu \mathrm { m } ]}]}\end{array}$ & Difference \\
\hline Side 1 & $1.789 \pm 0.094$ & $0.707 \pm 0.065$ & $60 \%$ \\
\hline Center & $1.789 \pm 0.094$ & $1.438 \pm 0.037$ & $20 \%$ \\
\hline Side 2 & $1.789 \pm 0.094$ & $1.634 \pm 0.030$ & $9 \%$ \\
\hline
\end{tabular}

The maximum replication is achievable for the high values of the factors. As the high value of the mold temperature was already set at the technological limit of the available experimental setup, only the other process parameters were increased up to the maximum values of $P_{\text {hold }}=400$ bar and $V_{\text {inj }}=$ $700 \mathrm{~mm} / \mathrm{s}$. With this optimal combination of process parameters the replication results reported in Table 4 were obtained.

The inadequate replication of the micro holes located close to gate is due to the hesitation of the polymer in that zone. This hypothesis was confirmed by the results of further experiments carried out varying only $V_{\text {inj }}$ on three levels: 200,500 and $700 \mathrm{~mm} / \mathrm{s}$. The effect of injection speed on the standard deviation of micro pillars height, plotted in Figure 3, clearly shows that for higher values of $V_{\text {inj, }}$, the reduced hesitation time contributes to make the pillars height distribution more uniform over the molded part.

The quality of the replication was also assessed by observing both the mold inserts (Figure 4) and the

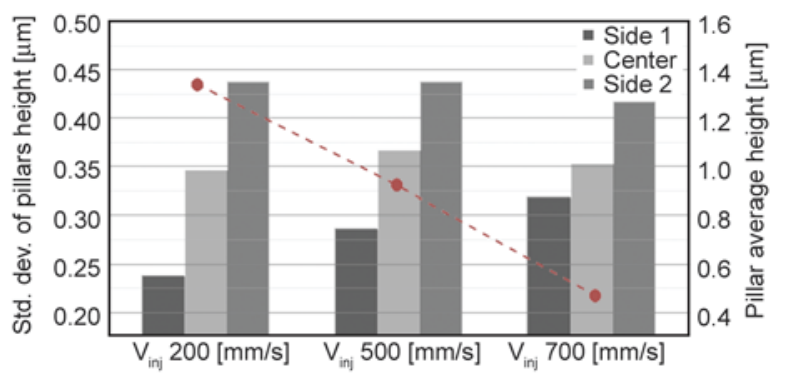

Figure 3. Influence of the injection speed on the standard deviation of micro pillars height along the diameter of the molded part $\left(P_{\text {hold }}=200 \mathrm{bar}, T_{\mathrm{m}}=90^{\circ} \mathrm{C}\right)$

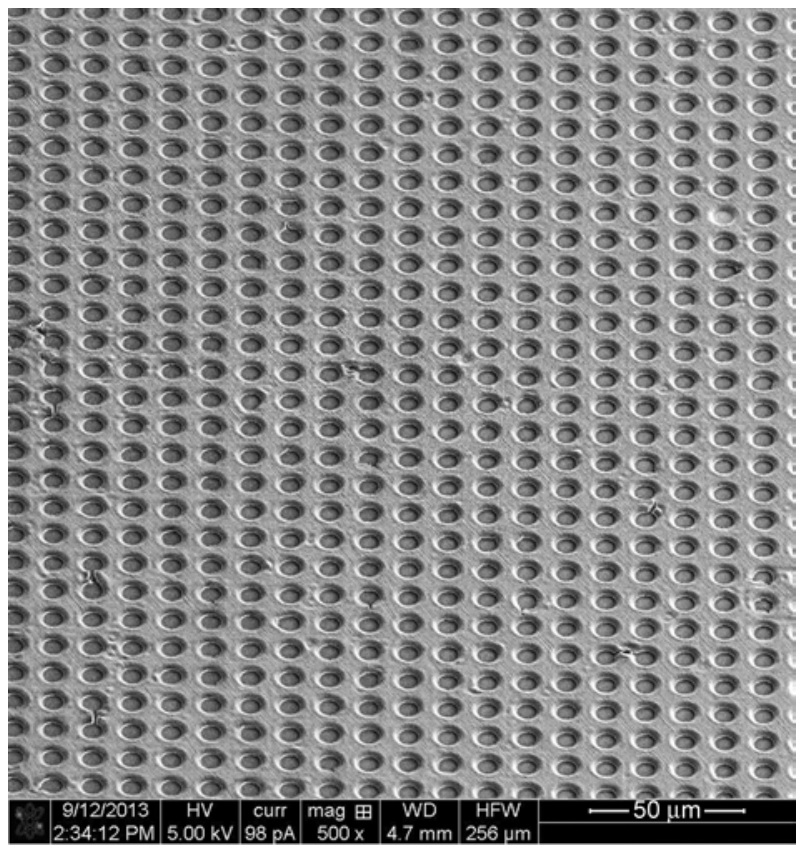

Figure 4. SEM micrographs of the micro holes in the pattern $4-10$ b insert

molded supports (Figure 5) by a Scanning Electron Microscope (FEI QUANTA 450).

Eventually, the optimal process parameters, determined by the experiments conducted using the insert 4-10b, were employed to produce supports with the inserts 2-8, 3-9 and 4-10a. The insert 4-10a instead of the $4-10 \mathrm{~b}$ was used in order to maximize the aspect ratio variation and therefore to analyze the cell growth dependence on pillars aspect ratio. The overall replication results are reported in Table 5.

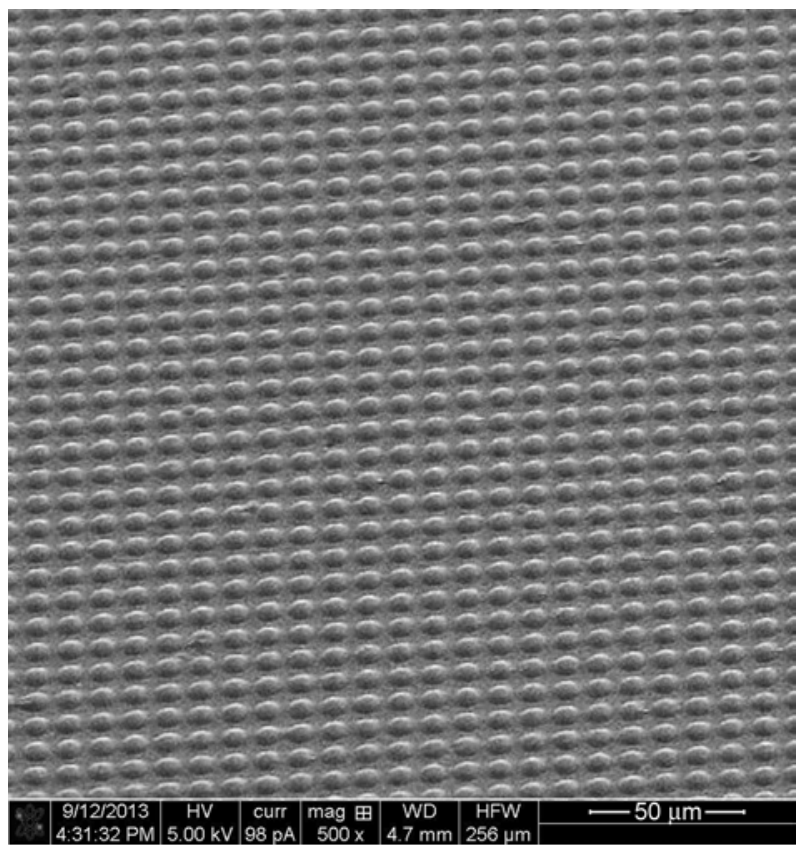

Figure 5. SEM micrographs of the micro pillars for the insert 4-10b 
Table 5. Replication of the micro holes

\begin{tabular}{|l|c|c|c|}
\hline \multicolumn{1}{|c|}{ Pattern } & $\mathbf{2 - 8}$ & $\mathbf{3 - 9}$ & $\mathbf{4 - 1 0 a}$ \\
\hline Holes depth, HD $[\mu \mathrm{m}]$ & 0.990 & 1.525 & 0.990 \\
\hline Pillars height, PH $[\mu \mathrm{m}]$ & 0.792 & 1.252 & 0.852 \\
\hline Replication degree, PH/HD & $80 \%$ & $82 \%$ & $86 \%$ \\
\hline Pillars aspect ratio & 0.396 & 0.417 & 0.213 \\
\hline Interspace $[\mu \mathrm{m}]$ & 7.999 & 9.012 & 10.020 \\
\hline
\end{tabular}

\subsection{Cells growth}

Our preliminary data reveal that the cells adhered and proliferated onto the micro-structured surface. Although cells adhered on all topographies at 1d, differences in cell morphology were noted (Figure 6). Indeed, the most of cells on modified inserts appeared flattened with several protrusions and less elongated that those observed on the smooth surfaces. Thus, as already observed by Justesen et al. [23] and

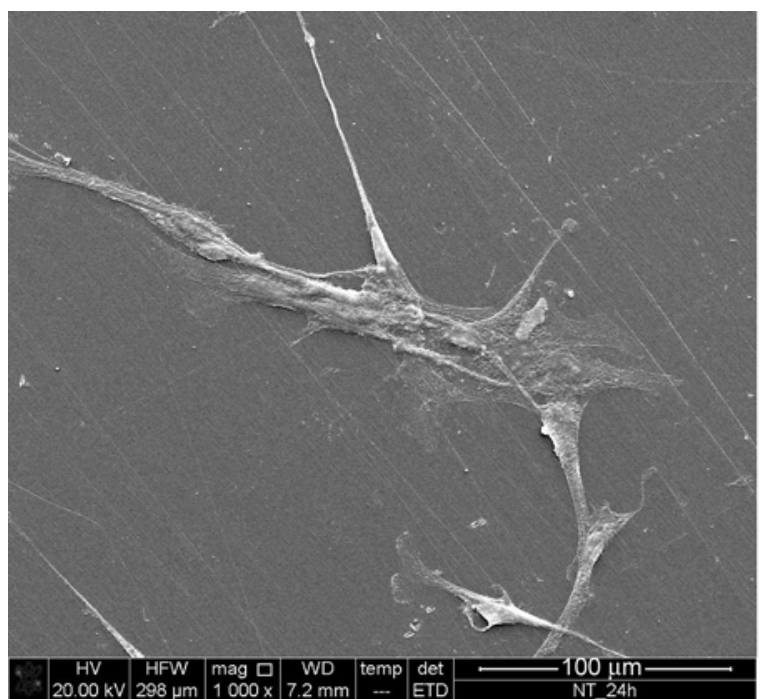

a)

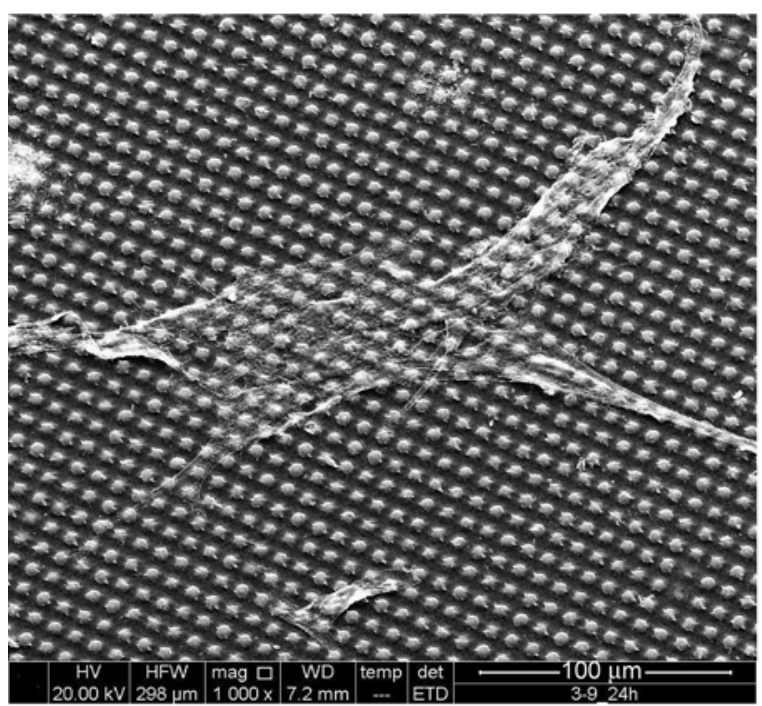

c) by Hamilton et al. [24], surface topography influences cell morphology and this, in turn, can modulate cell differentiation. However, the geometry of our micropillars had no effect on cell orientation and alignment, because cells cultured on modified surfaces were randomly oriented. To evaluate the effect of substrate topography on cell proliferation, cell number was determined at 1,3 and $7 \mathrm{~d}$ postseeding (Figure 7). On all cultural conditions no increases in cell number were detected between 1 and $3 \mathrm{~d}$. Since the inserts were composed of polystyrene not treated for cell cultures, this result was expected. Furthermore, at 1 and $3 \mathrm{~d}$ no differences in cell number were detected among cultures grown on pillar-structured surfaces and the control ones. On the contrary, at $7 \mathrm{~d}$ the cell numbers on all modified surfaces were significantly higher than that determined on control

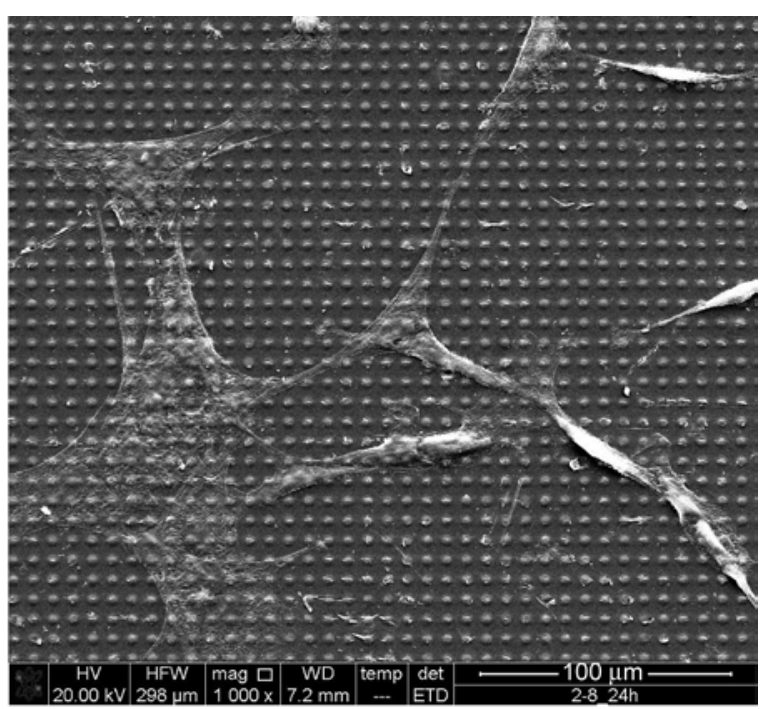

b)

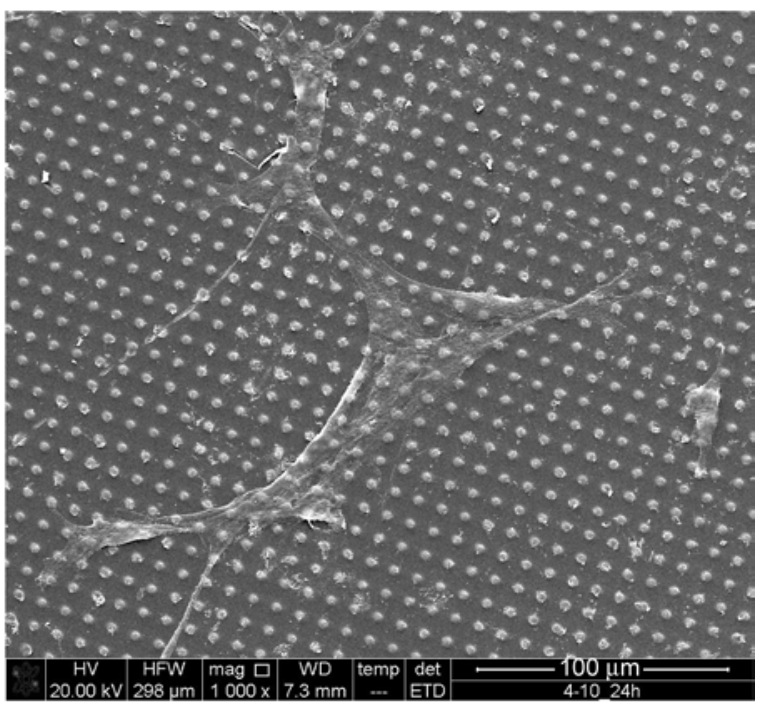

d)

Figure 6. SEM micrographs of cultures grown on smooth (a), 2-8 (b), 3-9 (c), and 4-10 (d) inserts at $1 \mathrm{~d}$ from seeding 


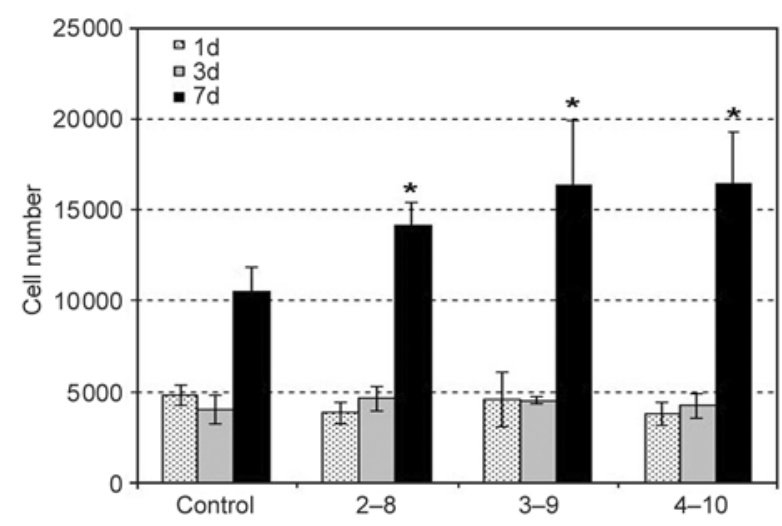

Figure 7. MTS assay at 1, 3, and $7 \mathrm{~d}$ after seeding. Results, expressed as cell number, are means $\pm \mathrm{SD}$ of three independent experiments. ${ }^{*}=p<0.05 \mathrm{vs}$ control cultures, Student's $t$-test

cultures. However, no statistical differences in cell growth were noted among the pillar-structured surfaces.

\section{Conclusions}

The micro injection molding process of micro-pillared polystyrene surfaces, performed on directly patternable silica-zirconia hybrid micro-structured mold inserts, was optimized to increase the degree of micro structures replication. The experimental results obtained from micro-pillared surfaces show that cells adhesion and proliferation is more positively promoted on micro-pillared surfaces compared to flat surfaces. Although mouse osteoblastic MC3T3-E1 cells well adhered on micro-pillared PS surface, indicating a positive cell-substrate interaction, no correlations were between cell proliferation and pillar diameter and spacing. To obtain more concrete results, future work would focus on varying the scale sizes, realizing nano pillars, as well as the array pattern. Meaningful results will help to form the groundwork for studying the effects of controlling cells differentiation towards osteogenic lineage using nano-structured topography.

\section{Acknowledgements}

The authors are grateful for the support of the Italian Ministry of Health (Grant: RF-2009-1528187).

\section{References}

[1] Kraus K. H., Kirker-Head C.: Mesenchymal stem cells and bone regeneration. Veterinary Surgery, 35, 232242 (2006).

DOI: 10.1111/j.1532-950X.2006.00142.x

[2] Habibovic P., de Groot K.: Osteoinductive biomaterials - Properties and relevance in bone repair. Journal of Tissue Engineering and Regenerative Medicine, 1, 25-32 (2007).

DOI: $10.1002 /$ term.5

[3] Hasirci V., Kenar H.: Novel surface patterning approaches for tissue engineering and their effect on cell behavior. Nanomedicine, 1, 73-90 (2006).

DOI: $10.2217 / 17435889.1 .1 .73$

[4] Flemming R. G., Murphy C. J., Abrams G. A., Goodman S. L., Nealey P. F.: Effects of synthetic micro- and nano-structured surfaces on cell behavior. Biomaterials, 20, 573-588 (1999).

DOI: $10.1016 / \mathrm{S} 0142-9612(98) 00209-9$

[5] Curtis A. S. G., Dalby M., Gadegaard N.: Cell signaling arising from nanotopography: Implications for nanomedical devices. Nanomedicine, 1, 67-72 (2006). DOI: $10.2217 / 17435889.1 .1 .67$

[6] Matsuzaka K., Walboomers X. F., Yoshinari M., Inoue T., Jansen J. A.: The attachment and growth behavior of osteoblast-like cells on microtextured surfaces. Biomaterials, 24, 2711-2719 (2003). DOI: 10.1016/S0142-9612(03)00085-1

[7] Recknor J. B., Recknor J. C., Sakaguchi D. S., Mallapragada S. K.: Oriented astroglial cell growth on micropatterned polystyrene substrates. Biomaterials, 25, 2753-2767 (2004).

DOI: $10.1016 /$ j.biomaterials.2003.11.045

[8] Clark P., Connolly P., Curtis A. S., Dow J. A., Wilkinson D. W.: Topographical control of cell behaviour: II. Multiple grooved substrata. Development, 108, 635-644 (1990).

[9] Keselowsky B. G., Wang L., Schwartz Z., Garcia A. J., Boyan B. D.: Integrin $\alpha_{5}$ controls osteoblastic proliferation and differentiation responses to titanium substrates presenting different roughness characteristics in a roughness independent manner. Journal of Biomedical Materials Research Part A, 80, 700-710 (2007). DOI: $10.1002 / \mathrm{jbm} . \mathrm{a} .30898$

[10] Kolind K., Dolatshahi-Pirouz A., Lovmand J., Pedersen F. S., Foss M., Besenbacher F.: A combinatorial screening of human fibroblast responses on micro-structured surfaces. Biomaterials, 31, 9182-9191 (2010).

DOI: $10.1016 /$ j.biomaterials.2010.08.048

[11] Engler A. J., Sen S., Sweeney H. L., Discher D. E.: Matrix elasticity directs stem cell lineage specification. Cell, 126, 677-689 (2006).

DOI: $10.1016 /$ j.cell.2006.06.044 
[12] Dalby M. J., Gadegaard N., Tare R., Andar A., Riehle M. O., Herzyk P., Wilkinson C. D. W., Oreffo R. O. C.: The control of human mesenchymal cell differentiation using nanoscale symmetry and disorder. Nature Materials, 6, 997-1003 (2007).

DOI: $10.1038 /$ nmat2013

[13] Hart A., Gadegaard N., Wilkinson C. D. W., Oreffo R. O. C., Dalby M. J.: Osteoprogenitor response to lowadhesion nanotopographies originally fabricated by electron beam lithography. Journal of Materials Science: Materials in Medicine, 18, 1211-1218 (2007). DOI: $10.1007 / \mathrm{s} 10856-007-0157-7$

[14] Angelov A., Coulter J., Jaafar I., Gomatam R., Kim Y., Rajagopalan P.: Realization of polymer-based nanostructured surfaces for biomedical applications via nanoscale injection molding. in 'SPE Annual Technical Conference and Exhibition. Denver, USA' 24892493 (2008).

[15] Yao D., Kim B.: Scaling issues in miniaturization of injection molded parts. Journal of Manufacturing Science and Engineering, 126, 733-739 (2004). DOI: $10.1115 / 1.1813479$

[16] Heckele M., Schomburg W. K.: Review on micro molding of thermoplastic polymers. Journal of Micromechanics and Microengineering, 14, R1-R14 (2004).

DOI: 10.1088/0960-1317/14/3/R01

[17] Lucchetta G., Sorgato M., Carmignato S., Savio E.: Investigating the technological limits of micro-injection molding in replicating high aspect ratio micro-structured surfaces. CIRP Annals - Manufacturing Technology, 63, 521-524 (2014).

DOI: $10.1016 /$ j.cirp.2014.03.049

[18] Griffiths C. A., Dimov S. S., Scholz S., Tosello G.: Cavity air flow behavior during filling in microinjection molding. Journal of Manufacturing Science and Engineering, 133, 011006/1-011006/10 (2011). DOI: $10.1115 / 1.4003339$
[19] Mönkkönen K., Pakkanen T. T., Hietala J., Pääkkönen E. J., Pääkkönen P., Jääskeläinen T., Kaikuranta T.: Replication of sub-micron features using amorphous thermoplastics. Polymer Engineering and Science, 42, 16001608 (2002).

DOI: 10.1002/pen.11055

[20] Lin H-Y., Chang C-H., Young W-B.: Experimental and analytical study on filling of nano structures in micro injection molding. International Communications in Heat and Mass Transfer, 37, 1477-1486 (2010). DOI: $10.1016 /$ j.icheatmasstransfer.2010.08.017

[21] Lucchetta G., Fiorotto M., Bariani P. F.: Influence of rapid mold temperature variation on surface topography replication and appearance of injection-molded parts. CIRP Annals - Manufacturing Technology, 61, 539542 (2012). DOI: 10.1016/j.cirp.2012.03.091

[22] Tosello G., Gava A., Hansen H. N., Lucchetta G.: Influence of process parameters on the weld lines of a micro injection molded component. in 'Conference Proceedings of Annual Technical Conference - ANTEC, Cincinnati, USA' Vol 4, 2002-2006 (2007).

[23] Justesen J., Lorentzen M., Andersen L. K., Hansen O., Chevallier J., Modin C., Füchtbauer A., Foss M., Besenbacher F., Duch M., Pedersen F. S.: Spatial and temporal changes in the morphology of preosteoblastic cells seeded on microstructured tantalum surfaces. Journal of Biomedical Materials Research Part A, 89, 885-894 (2009).

DOI: $10.1002 / \mathrm{jbm} \cdot a \cdot 32032$

[24] Hamilton D. W., Wong K. S., Brunette D. M.: Microfabricated discontinuous-edge surface topographies influence osteoblast adhesion, migration, cytoskeletal organization, and proliferation and enhance matrix and mineral deposition in vitro. Calcified Tissue International, 78, 314-325 (2006).

DOI: $10.1007 / \mathrm{s} 00223-005-0238-\mathrm{X}$ 